\title{
Free Vibration of Angle-ply Laminated Conical Shell Frusta with Linear and Exponential Thickness Variations
}

\author{
K. K. Viswanathan \\ Department of Mathematics, Kuwait College of Science and Technology, Doha District, Block 4, P.O. Box No. \\ 27135, Safat 13133, Kuwait. \\ UTM Centre for Industrial and Applied Mathematics, Ibnu Sina Institute for Scientific \& Industrial Research, \\ Universiti Teknologi Malaysia, 81310 Skudai, Johor Bahru, Johor, Malaysia.
}

\author{
A. K. Nor Hafizah and Z. A. Aziz \\ Department of Mathematical Sciences, Faculty of Science, Universiti Teknologi Malaysia, 81310 Skudai, Johor \\ Bahru, Johor, Malaysia. \\ UTM Centre for Industrial and Applied Mathematics, Ibnu Sina Institute for Scientific \& Industrial Research, \\ Universiti Teknologi Malaysia, 81310 Skudai, Johor Bahru, Johor, Malaysia.
}

(Received 19 October 2015; accepted 26 August 2016)

\begin{abstract}
Free vibration of laminated conical shell frusta of variable thickness is studied using spline approximation. This problem includes first order shear deformation and considers shells as antisymmetric angle-ply orientation. The governing differential equations of the shells are resolved in terms of displacement functions and rotational functions. These functions are approximated using splines and the method of collocation is adopted for simultaneous algebraic equations. These equations become generalized eigenvalue problems and are solved numerically to avail eigenfrequencies and the corresponding eigenvectors. The variation of frequencies is analysed with respect to the cone angle, aspect ratio, material properties, number of layers, and thickness variation.
\end{abstract}

\section{INTRODUCTION}

To build a stable and sturdy construction in engineering industries, it is necessary to study the vibration analysis of the structures. This means that the structures should be designed with consideration to factors such as frequency parameter, materials, and orientation in order to construct highly reinforced structures. Thin shells play an important role as structural elements in industries because of their great range of desirable properties such as high degrees of reserved strength and structural integrity. Large-span roofs, water tanks, aircraft, and submarine are all examples of shell structures that can be found in engineering industries. Shell structures made up of composite materials have been used significantly as they possess high specific stiffness, better damping, and shock absorbing characteristics.

The study of conical shells enables engineers to meet the demand of industries. A number of analytical and numerical studies were conducted on the static and free vibration analysis of conical shells. Free vibration of laminated conical shells was studied by $\mathrm{Wu}$ and Wu using asymptotic differential quadrature (DQ) solutions. ${ }^{1}$ Tong developed a solution using power series method to solve free vibration of orthotropic conical shells using the Donnell-type classical shell theory with and without shear deformation effects. ${ }^{2-4}$ Shu conducted a free vibration analysis on composite laminated conical shells using generalized quadrature method (GDQ) where the method approximate a spatial derivative of a function with respect to a coordinate at a discrete point as a weighted linear sum of all the functional values in the whole domain. ${ }^{5}$ GDQ was also used by $\mathrm{Ng}$ et al. to investigate the orthotropic influence of composite materials on frequency characteristics for a rotating thin truncated circular symmetrical cross-ply laminated composite conical shell with different boundary conditions. ${ }^{6}$ Civalek presented discrete singular convolution method (DSC) for the vibration analysis of conical shells. ${ }^{7}$ Civalek continued this research, determining the frequencies of the free vibration of laminated conical shell including shear deformation theory. ${ }^{8}$ Liew et al. and Liew and Zhou used element-free kpRitz method to study the free vibration of conical shells and functionally graded conical shells respectively. ${ }^{9,10}$

Studies on vibration of conical shells were conducted by Viswanathan et al. for free vibration of cross-ply and angle-ply laminated truncated shells using spline method. ${ }^{11-13}$ A study on free vibration analysis of multiple delaminated angle-ply composite conical shells using finite element method (FEM) was performed by Dey and Karmakar using QR iteration algorithm. ${ }^{14}$ In order to study the free vibration of simply supported circular cylindrical shells, a semi-analytical procedure was introduced by Farshidianfar and Olizadech for simplysupported boundary condition. ${ }^{15}$ A modified Fourier series was used by Jin et al. to analyse the vibration of truncated conical shells with general boundary conditions and the effect of elastic restraint parameters, semi-vertex angle and the ratio of length to radius. ${ }^{16}$

Malekzadech and Daraie presented a study on the dynamic behaviour of functionally graded (FG) truncated conical shells subjected to asymmetric internal ring-shaped moving loads. ${ }^{17}$ 
He used FEM alongside Newmark's time integration scheme to discretize the equations of motion in the spatial and temporal domain, respectively to solve the problem. Ma et al. used Fourier-Ritz method to solve the problem for free and forced vibration analysis of coupled conical-cylindrical shells with arbitrary boundary conditions. ${ }^{18}$ Free vibration analysis of fibre reinforced composite (FRC) conical shells resting on Pasternak-type elastic foundation was investigated by Zaroumi et al. using Galerkin and Ritz methods. ${ }^{19}$ A study on conical shells was conducted by Heydarpour et al. in which they applied the differential quadrature method (DQM) to solve free vibration analysis of rotating functionally graded carbon nanotube-reinforced composite truncated conical shells based on the first order shear deformation theory of shells. ${ }^{20}$

The vibration analysis of conical shells with variable thickness has been studied by some researchers using a few methods. Irie et al. analysed free vibration of truncated conical shell with variable thickness through use of the transfer matrix approach. ${ }^{21}$ Sankaranarayanan et al. conducted a study on vibrations of laminated conical shells of variable thickness based on classical thin shell theory using Rayleigh-Ritz procedure. ${ }^{22}$ Takahashi et al. used Ritz method to study the vibration of conical shells with variable thickness. ${ }^{23}$ Sivadas and Ganesan studied the free vibration of cantilever conical shells with variable thickness by using semi-analytical finite element method. ${ }^{24}$ Later, they performed a study on the vibration of laminated conical shells with variable thickness using the same method. ${ }^{25}$ Kang proposed a three-dimensional (3D) method of analysis for determining the free vibration frequencies of complete conical shells with linearly varying thickness. ${ }^{26}$ Selahi et al. developed a hybrid method based on 3D elasticity theory for transient analysis of FG truncated conical shell with variable thickness. ${ }^{27}$ Also, Mehdi et al. conducted a thermo-elastic analysis of axially functionally graded rotating thick truncated conical shells with varying thickness using multi-layer method $(\mathrm{MLM}){ }^{28}$

This study investigates free vibration of antisymmetric angle-ply conical shells with linear and exponential variation in thickness under first order shear deformation theory (FSDT). The spline function approximation technique used here is preferable to other methods, since, in this study, a chain of lower order approximations can yield greater accuracy than a global higher order approximation. Also, polynomials of high degrees when applied to a large number of given data points tends to exhibit more numerous undulations than a curve drawn by spline. Hence, spline function is a more adaptable approximating function than a polynomial involving a comparable number of parameters. Another disadvantage of polynomial approximations is that, if the function to be approximated is badly behaved anywhere in the interval of approximation, then the approximation is poor everywhere. This global dependence on local properties is avoidable with the use of splines. This conjuncture was made and tested by Bickley over a two-point boundary value problem with a cubic spline. ${ }^{29}$ The layers of conical shell are considered to be thin, elastic, and specially orthotropic or isotropic. Stress-strain relations and strain-displacement relations are substituted into the equilibrium equation of the conical shell to obtain the governing differential equations in terms of mid-plane displacement compo- nents and shear rotation. Governing differential equations are assumed in the separable form and then reduced to a system of ordinary differential equations on a set of displacement functions. Bickley-type spline is used to approximate the displacement functions. The field equations along with the equations of boundary conditions reduced into a system of homogenous simultaneous algebraic equations on the assumed spline coefficients. The clamped-clamped and simply-supported boundary conditions are considered. The frequencies are obtained using eigensolution techniques since the problem is considered as eigenvalue problem with spline coefficients as eigenvectors. For this work, two types of layered materials are used and arranged in antisymmetric angle-ply orientation. The thickness variation, cone angle, aspect ratio, circumferential node number, and boundary conditions are taken into consideration in calculating the frequency parameters. The findings are presented and discussed in terms of graphs and tables.

\section{THEORETICAL FORMULATION}

Consider a composite laminated truncated conical shell with an arbitrary number of layers that are perfectly bonded together. The orthogonal coordinate system $x, \theta, z$ is fixed at its reference surface, which is assumed to be at the middle surface. The radius of the cone at any point along its length is $r=x \sin \alpha$. The radius at the small end of the cone is $r_{a}=a \sin \alpha$, the other end is $r_{b}=b \sin \alpha$ and 1 is the length of the cone.

The displacement components are assumed to be in the form

$$
\begin{aligned}
u(x, \theta, z, t) & =u_{0}(x, \theta, t)+z \psi_{x}(x, \theta, t) ; \\
v(x, \theta, z, t) & =v_{0}(x, \theta, t)+z \psi_{\theta}(x, \theta, t) ; \\
w(x, \theta, z, t) & =w_{0}(x, \theta, t) ;
\end{aligned}
$$

where $u_{0}, v_{0}$, and $w_{0}$ are the displacements of the shell in the mid-plane, $\psi_{x}$ and $\psi_{\theta}$ are the shear rotations of any point on the middle surface of the shell. ${ }^{11}$ The stress-resultants and moment-resultants are given as

$$
\begin{aligned}
\left(N_{x}, N_{\theta}, N_{x \theta}, Q_{x z}, Q_{\theta z}\right) & =\int_{z}\left(\sigma_{x}, \sigma_{\theta}, \tau_{x \theta}, \tau_{x z}, \tau_{\theta z}\right) d z \\
\left(M_{x}, M_{\theta}, M_{x \theta}\right) & =\int_{z}\left(\sigma_{x}, \sigma_{\theta}, \tau_{x \theta}\right) d z
\end{aligned}
$$

The equations of stress-resultants and moment-resultants are obtained as follows:

$$
\begin{gathered}
{\left[\begin{array}{c}
N_{x} \\
N_{\theta} \\
N_{x \theta} \\
M_{x} \\
M_{\theta} \\
M_{x \theta}
\end{array}\right]=\left[\begin{array}{llllll}
A_{11} & A_{12} & A_{16} & B_{11} & B_{12} & B_{16} \\
A_{12} & A_{22} & A_{26} & B_{12} & B_{22} & B_{26} \\
A_{16} & A_{26} & A_{66} & B_{16} & B_{26} & B_{66} \\
B_{11} & B_{12} & B_{16} & D_{11} & D_{12} & D_{16} \\
B_{12} & B_{22} & B_{26} & D_{12} & D_{22} & D_{26} \\
B_{16} & B_{26} & B_{66} & D_{16} & D_{26} & D_{66}
\end{array}\right] .} \\
\\
{\left[\begin{array}{c}
\frac{1}{x} u_{0}+\frac{1}{x \sin \alpha} \frac{\partial v_{0}}{\partial \theta}+\frac{1}{x \tan \alpha} w \\
\frac{1}{x \sin \alpha} \frac{\partial u_{0}}{\partial \theta}+\frac{\partial v_{0}}{\partial x}-\frac{1}{x} v_{0} \\
\frac{\partial \psi_{x}}{\partial x} \\
\frac{1}{x} \psi_{x}+\frac{1}{x \sin \alpha} \frac{\partial \psi_{\theta}}{\partial \theta} \\
\frac{1}{x \sin \alpha} \frac{\partial \psi_{x}}{\partial \theta}+\frac{\partial \psi_{\theta}}{\partial x}-\frac{1}{x} \psi_{\theta}
\end{array}\right] ;}
\end{gathered}
$$


Table 1. Convergence study of fundamental frequency parameter $\lambda$ of antisymmetric angle-ply conical shells with linear thickness variation using KGEKGE material combination under $\mathrm{C}-\mathrm{C}$ boundary conditions.

\begin{tabular}{|c|c|c|}
\hline \multicolumn{3}{|c|}{$\beta=0.5, \gamma=0.05, \eta=0.75$} \\
\hline $\mathrm{N}$ & $\lambda_{1}$ & $\%$ change \\
\hline 4 & 0.437932 & - \\
6 & 0.336534 & -23.154 \\
8 & 0.295677 & -12.141 \\
10 & 0.275403 & -6.857 \\
12 & 0.263968 & -4.152 \\
14 & 0.256922 & -2.669 \\
16 & 0.252287 & -1.804 \\
18 & 0.249081 & -1.271 \\
20 & 0.246774 & -0.926 \\
\hline
\end{tabular}

and

$$
\left[\begin{array}{l}
Q_{\theta z} \\
Q_{x z}
\end{array}\right]=K\left[\begin{array}{ll}
A_{44} & A_{45} \\
A_{45} & A_{55}
\end{array}\right]\left[\begin{array}{c}
\psi_{\theta}+\frac{1}{x \sin \alpha} \frac{\partial w}{\partial \theta}-\frac{1}{x \tan \alpha} v_{0} \\
\psi_{x}+\frac{\partial w}{\partial x}
\end{array}\right]
$$

where we define the elastic coefficients $A_{i j}, B_{i j}$, and $D_{i j}$ as extensional stiffness, bending-extensional coupling stiffness, and bending stiffness respectively and $K$ is the shear correction factor. The value for the shear correction factor $K$ is chosen from the lamination scheme. The procedure for finding the values of shear correction factors have been explored by Whitney. ${ }^{30}$ The elastic coefficients $A_{i j}, B_{i j}$, and $D_{i j}$ corresponding to layers of uniform thickness with superscript ' $c$ ' are assumed to be in the form

$$
\begin{aligned}
& A_{i j}=A_{i j}^{c} g(x) ; \quad B_{i j}=B_{i j}^{c} g(x) ; \quad D_{i j}=D_{i j}^{c} g(x) ; \\
& A_{i j}^{c}=\sum_{k} \bar{Q}_{i j}^{(k)}\left(z_{k}-z_{k-1}\right), \\
& B_{i j}^{c}=\frac{1}{2} \sum_{k} \bar{Q}_{i j}^{(k)}\left(z_{k}^{2}-z_{k-1}^{2}\right), \\
& D_{i j}^{c}=\frac{1}{3} \sum_{k} \bar{Q}_{i j}^{(k)}\left(z_{k}^{3}-z_{k-1}^{3}\right) \quad \text { for } i, j=1,2,6 ; \\
& A_{i j}^{c}=K \sum_{k} \bar{Q}_{i j}^{(k)}\left(z_{k}-z_{k-1}\right) \quad \text { for } i, j=4,5 ;
\end{aligned}
$$

and $z_{k-1}$ and $z_{k}$ are boundaries of $k$-th layer.

In this study, the thickness variation of the $k$-th layer of the shell is assumed in the form of

$$
h_{k}(x)=h_{0 k} g(x)
$$

where $g(x)=1+C_{l}\left(x-x_{a} / l\right)+C_{e} \exp \left(x-x_{a} / l\right), C_{l}=$ $1 / \eta-1, \eta$ is the taper ratio, $h_{0 k}$ is a constant thickness of the $k$-th layer, $l=b-a$ is the length of the cone, $x_{a}$ is the distance from origin to $x=a$ (small end of the cone), and $C_{l}$ and $C_{e}$ are the coefficients of linear thickness in variation. The thickness of the shell becomes uniform when $g(x)=1$.

The displacement components $u_{0}, v_{0}, w$ and shear rotations $\psi_{x}, \psi_{\theta}$ are assumed in the separable form given as

$$
\begin{aligned}
u_{0}(x, \theta, t) & =U(x) e^{n \theta} e^{i \omega t} ; \\
v_{0}(x, \theta, t) & =V(x) e^{n \theta} e^{i \omega t} ; \\
w(x, \theta, t) & =W(x) e^{n \theta} e^{i \omega t} ; \\
\psi_{x}(x, \theta, t) & =\Psi_{X}(x) e^{n \theta} e^{i \omega t} ; \\
\psi_{\theta}(x, \theta, t) & =\Psi_{\Theta}(x) e^{n \theta} e^{i \omega t} ;
\end{aligned}
$$

Table 2. Comparison of fundamental frequency for isotropic conical shells $\left(\alpha=45^{\circ}\right)$.

\begin{tabular}{|c|c|c|c|c|c|}
\hline$n$ & Irie et al. & Lam and Hu & Daneshjou et al. & Jin et al. & Present \\
\hline 1 & 0.8120 & 0.8452 & 0.8128 & 0.8119 & 0.8427 \\
2 & 0.6696 & 0.6803 & 0.6713 & 0.6695 & 0.7488 \\
3 & 0.5430 & 0.5553 & 0.5449 & 0.5428 & 0.5609 \\
4 & 0.4570 & 0.4778 & 0.4588 & 0.4566 & 0.4953 \\
5 & 0.4095 & 0.4395 & 0.4108 & 0.4089 & 0.4299 \\
\hline
\end{tabular}

where $\omega$ is the angular frequency of vibration, $t$ is the time, and $n$ is the circumferential node number. The non-dimensional parameters are written as follows:

$X=\frac{x-a}{l}, a \leq x \leq b$ and $X \in[0,1]$

$\lambda=\omega l \sqrt{\frac{I_{1}}{A_{11}}}-$ frequency parameter;

$\gamma=\frac{h}{r_{a}}, \gamma^{\prime}=\frac{h}{a}-$ ratios of thickness to radius and to length;

$\beta=\frac{a}{b}-$ length ratio;

$\delta_{k}=\frac{h_{k}}{h}-$ relative layer thickness of the $k$-th layer.

The thickness $h_{k}(X)$ of the $k$-th layer at $X$ distance from the smaller end of the cone can be written as

$$
h_{k}(X)=h_{0 k} g(X)
$$

where $g(X)=1+C_{l}(X)+C_{e} \exp (X)$.

Substituting Eqs. (3) and (4) into the equation of motion of conical shells and applying the condition of antisymmetric in angle-ply laminates (i.e., $A_{16}, A_{26}, A_{45}, B_{11}, B_{12}, B_{22}, B_{66}$, $D_{16}$ and $D_{26}$ are identically zero), the differential equations in terms of displacement functions and rotational function are obtained. ${ }^{12}$ Then, applying Eq. (7) into the obtained differential equations and using the non-dimensional parameters given in Eq. (8), we get a new differential equation in terms of $X$ written in matrix form as

$$
\left[\begin{array}{lllll}
L_{11} & L_{12} & L_{13} & L_{14} & L_{15} \\
L_{21} & L_{22} & L_{23} & L_{24} & L_{25} \\
L_{31} & L_{32} & L_{33} & L_{34} & L_{35} \\
L_{41} & L_{42} & L_{43} & L_{44} & L_{45} \\
L_{51} & L_{52} & L_{53} & L_{54} & L_{55}
\end{array}\right]\left[\begin{array}{c}
U \\
V \\
W \\
\Psi_{X} \\
\Psi_{\Theta}
\end{array}\right]=\left[\begin{array}{l}
0 \\
0 \\
0 \\
0 \\
0
\end{array}\right]
$$

The differential operators $L_{i j}$ of the matrix are given in Appendix A.

\section{SOLUTION PROCEDURE}

\subsection{Spline Collocation Method}

The displacement functions $U(X), V(X), W(X)$ and shear rotational functions $\Psi_{X}, \Psi_{\Theta}$ are approximated by the cubic 
Table 3. Effect of taper ratio on fundamental frequency parameter for two-layered and four-layered antisymmetric angle-ply shells under C-C boundary condition.

\begin{tabular}{|c|c|c|c|c|c|c|}
\hline $\begin{array}{c}|c| \\
(\mathrm{C}-\mathrm{C})\end{array}$ & $30^{\circ} /-30^{\circ}$ & $45^{\circ} /-45^{\circ}$ & $60^{\circ} /-60^{\circ}$ & $30^{\circ} /-30^{\circ} / 30^{\circ} /-30^{\circ}$ & $45^{\circ} /-45^{\circ} / 45^{\circ} /-45^{\circ}$ & $60^{\circ} /-60^{\circ} / 60^{\circ} /-60^{\circ}$ \\
\hline 0.5 & 1.705182 & 1.490318 & 2.29726 & 1.42444 & 1.32304 & 1.970109 \\
0.7 & 1.708879 & 1.490695 & 2.276687 & 1.42754 & 1.31681 & 1.965038 \\
0.9 & 1.718141 & 1.490702 & 2.262988 & 1.42894 & 1.31159 & 1.959725 \\
1.1 & 1.713475 & 1.491801 & 2.245690 & 1.42962 & 1.30378 & 1.952383 \\
1.3 & 1.722526 & 1.491454 & 2.234581 & 1.43036 & 1.30173 & 1.947813 \\
1.5 & 1.716608 & 1.491069 & 2.224776 & 1.42981 & 1.29638 & 1.942269 \\
1.7 & 1.717887 & 1.490648 & 2.216387 & 1.42835 & 1.29303 & 1.934020 \\
1.9 & 1.721095 & 1.490266 & 2.208637 & 1.42738 & 1.28982 & 1.933757 \\
\hline
\end{tabular}

Table 4. Effect of taper ratio on fundamental frequency parameter for two-layered and four-layered antisymmetric angle-ply shells under S-S boundary condition.

\begin{tabular}{|c|c|c|c|c|c|c|}
\hline$\eta$ & \multicolumn{5}{|c|}{$\lambda$} \\
\cline { 2 - 6 }$(\mathrm{S}-\mathrm{S})$ & $30^{\circ} /-30^{\circ}$ & $45^{\circ} /-45^{\circ}$ & $60^{\circ} /-60^{\circ}$ & $30^{\circ} /-30^{\circ} / 30^{\circ} /-30^{\circ}$ & $45^{\circ} /-45^{\circ} / 45^{\circ} /-45^{\circ}$ & $60^{\circ} /-60^{\circ} / 60^{\circ} /-60^{\circ}$ \\
\hline 0.5 & 1.300378 & 1.403061 & 2.046212 & 0.992034 & 1.276639 & 1.51583 \\
0.7 & 1.275566 & 1.397328 & 1.914694 & 0.930002 & 1.236238 & 1.47639 \\
0.9 & 1.204745 & 1.381609 & 1.864453 & 0.887438 & 1.175017 & 1.47844 \\
1.1 & 1.146880 & 1.369522 & 1.819716 & 0.876579 & 1.152948 & 1.44300 \\
1.3 & 1.102348 & 1.119105 & 1.776701 & 0.876694 & 1.133833 & 1.44309 \\
1.5 & 1.056352 & 1.100282 & 1.736113 & 0.842458 & 1.116575 & 1.43035 \\
1.7 & 1.020276 & 1.10031 & 1.662452 & 0.829011 & 1.116822 & 1.41038 \\
1.9 & 0.988152 & 1.100148 & 1.665756 & 0.829124 & 1.116575 & 1.40947 \\
\hline
\end{tabular}

Table 5. Effect of exponential variation of thickness on fundamental frequency parameter for two-layered and four-layered antisymmetric angle-ply shells under C-C boundary condition.

\begin{tabular}{|c|c|c|c|c|c|c|}
\hline \hline$C_{e}$ & \multicolumn{5}{|c|}{$\lambda$} \\
\cline { 2 - 7 }$(\mathrm{C}-\mathrm{C})$ & $30^{\circ} /-30^{\circ}$ & $45^{\circ} /-45^{\circ}$ & $60^{\circ} /-60^{\circ}$ & $30^{\circ} /-30^{\circ} / 30^{\circ} /-30^{\circ}$ & $45^{\circ} /-45^{\circ} / 45^{\circ} /-45^{\circ}$ & $60^{\circ} /-60^{\circ} / 60^{\circ} /-60^{\circ}$ \\
\hline-0.2 & 0.942119 & 1.11540 & 1.55161 & 0.29646 & 0.42921 & 1.000617 \\
-0.1 & 0.945672 & 1.12045 & 1.55612 & 0.29991 & 0.43544 & 1.004171 \\
0.0 & 0.947293 & 1.12161 & 1.55801 & 0.30153 & 0.43848 & 1.005617 \\
0.1 & 0.948080 & 1.12232 & 1.55890 & 0.30239 & 0.44019 & 1.006293 \\
0.2 & 0.948461 & 1.12269 & 1.55939 & 0.30290 & 0.44124 & 1.006645 \\
\hline
\end{tabular}

Table 6. Effect of exponential variation of thickness on fundamental frequency parameter for two-layered and four-layered antisymmetric angle-ply shells under S-S boundary condition.

\begin{tabular}{|c|c|c|c|c|c|c|}
\hline \hline$C_{e}$ & \multicolumn{7}{|c|}{$\lambda$} \\
\cline { 2 - 7 }$(\mathrm{S}-\mathrm{S})$ & $30^{\circ} /-30^{\circ}$ & $45^{\circ} /-45^{\circ}$ & $60^{\circ} /-60^{\circ}$ & $30^{\circ} /-30^{\circ} / 30^{\circ} /-30^{\circ}$ & $45^{\circ} /-45^{\circ} / 45^{\circ} /-45^{\circ}$ & $60^{\circ} /-60^{\circ} / 60^{\circ} /-60^{\circ}$ \\
\hline-0.2 & 0.727035 & 0.95569 & 1.10094 & 0.084430 & 0.295550 & 0.35790 \\
-0.1 & 0.84608 & 1.01571 & 1.27023 & 0.21235 & 0.221520 & 0.42245 \\
0 & 0.879383 & 0.95568 & 1.36164 & 0.26676 & 0.386550 & 0.49541 \\
0.1 & 0.915486 & 1.07887 & 1.42196 & 0.30077 & 0.386544 & 0.49544 \\
0.2 & 0.915464 & 0.94855 & 1.46537 & 0.300764 & 0.386545 & 0.49544 \\
\hline
\end{tabular}

spline functions as presented below:

$$
\begin{aligned}
U(X) & =\sum_{i=0}^{2} a_{i} X^{i}+\sum_{j=0}^{N-1} b_{j}\left(X-X_{j}\right)^{3} H\left(X-X_{j}\right) \\
V(X) & =\sum_{i=0}^{2} c_{i} X^{i}+\sum_{j=0}^{N-1} d_{j}\left(X-X_{j}\right)^{3} H\left(X-X_{j}\right) \\
W(X) & =\sum_{i=0}^{2} e_{i} X^{i}+\sum_{j=0}^{N-1} f_{j}\left(X-X_{j}\right)^{3} H\left(X-X_{j}\right) ; \\
\Psi_{X}(X) & =\sum_{i=0}^{2} g_{i} X^{i}+\sum_{j=0}^{N-1} p_{j}\left(X-X_{j}\right)^{3} H\left(X-X_{j}\right) ; \\
\Psi_{\Theta}(X) & =\sum_{i=0}^{2} l_{i} X^{i}+\sum_{j=0}^{N-1} q_{j}\left(X-X_{j}\right)^{3} H\left(X-X_{j}\right) ;
\end{aligned}
$$

where $H\left(X-X_{j}\right)$ is the Heavyside step function and $N$ is the number of sub-intervals within the range $[0,1]$ of $X$ divided. The collocation points are the knots of the splines at $X=X_{s}=s / N$, where $s=0,1, \ldots, N$. Considering the condition that the differential equations given by Eq. (10) are satisfied by these splines at the knots, a set $5 N+5$ homogenous equations in $5 N+15$ unknown spline coefficients, $a_{i}, c_{i}$, $e_{i}, g_{i}, l_{i}, b_{j}, d_{j}, f_{j}, p_{j}, q_{j}(i=0,1,2 ; j=0,1,2, \ldots, N-1)$ is obtained.

\subsection{Boundary Conditions}

Two boundary conditions are used to analyse the problem.

(i) Clamped-Clamped (C-C) (both the ends are clamped) $U=V=W=\Psi_{X}=\Psi_{\Theta}=0$ at $X=0$ and $X=1$.

(ii) Simply-Supported (S-S) (both ends are simply supported) $V=W=N_{X}=M_{X}=\Psi_{\Theta}=0$ at $X=0$ and $X=1$.

Each boundary condition gives 10 equations on spline coefficients. Gathering them with those obtained earlier, we get $5 N+15$ homogenous equations, with the same number unknown. Hence, the system of equations can be written in the form

$$
[P][q]=\Lambda[Q][q]
$$




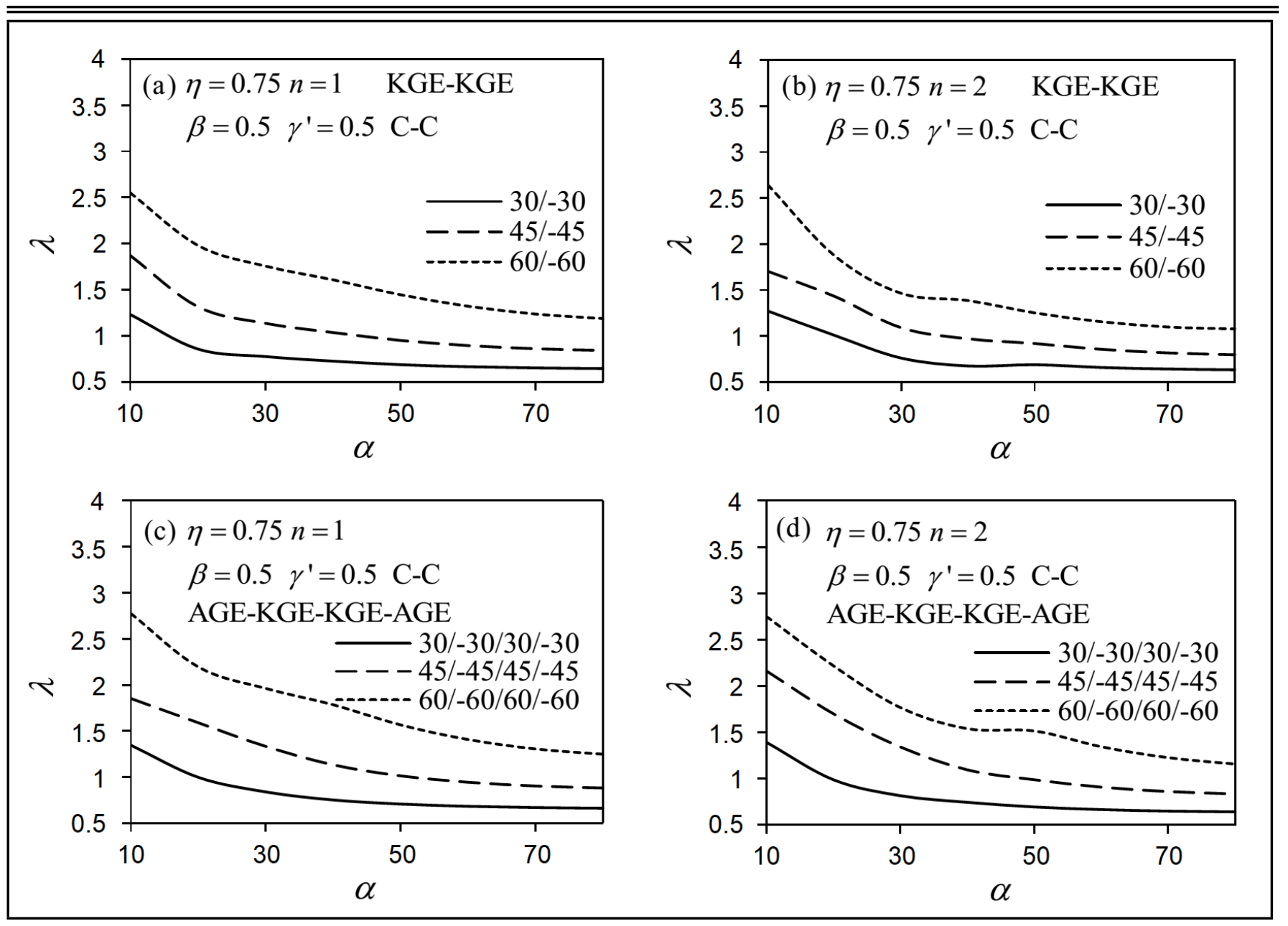

Figure 1. Effect of cone angle on fundamental frequency parameter of two-layered and four-layered conical shells under C-C boundary condition: linear variation in thickness.

Here $[P]$ and $[Q]$ are square matrices, $[q]$ is a column matrix, and $\Lambda=1 / \lambda^{2}$, where $\lambda$ is the frequency parameter. $\Lambda$ or $\lambda^{2}$ is the eigenparameter and $[q]$ is the eigenvector for this generalized eigenvalue problem.

\section{RESULT AND DISCUSSION}

In this work, convergence study for the frequency parameter $\lambda$ has been calculated to choose the number of subintervals $N$ of the spline function. As shown in Table 1, the program is performed for $N=2$ ( $N$ being number of knots) and onwards; It is seen that $N=18$ would be enough to achieve low change in percentage. In order to verify the results, the reduced case of constant thickness is compared with the value of fundamental frequency $\lambda$ obtained by Daneshjou et al., Lam and Hua, Irie et al., and Jin et al. presented in Table $2 .{ }^{16,31-33}$

In this study, the frequency parameter $\lambda$ for antisymmetric angle-ply of conical shells is investigated using two different material properties, i.e., Graphite Epoxy (AS4/3501-6) (AGE) and Kevler-49 Epoxy (KGE). Two and four layers of materials are considered to analyse the problem where the materials are arranged in the form of KGE-KGE and AGE-KGE-KGE-AGE respectively. The layers with the plyangles are oriented in the form of $30^{\circ} /-30^{\circ}, 45^{\circ} /-45^{\circ}$, $60^{\circ} /-60^{\circ}, 30^{\circ} /-30^{\circ} / 30^{\circ} /-30^{\circ}, 45^{\circ} /-45^{\circ} / 45^{\circ} /-45^{\circ}$ and $60^{\circ} /-60^{\circ} / 60^{\circ} /-60^{\circ}$. Clamped-Clamped (C-C: both the edges are clamped) and Simply-supported (S-S: both the edges are simply supported) boundary conditions are considered. The thickness variation is assumed to be in linear and exponential.

Table 3 depicts the influence of taper ratio $\eta$ on the fundamental frequency parameter $\lambda$ for two-layered and fourlayered antisymmetric angle-ply shells under C-C boundary condition. The value of $\eta$ ranges for $0.5 \leq \eta \leq 1.9$. The parameters such as circumferential node number $n=1$, length ratio $\beta=0.5$ and ratio of thickness to radius $\gamma=0.05$ are fixed. In Table 3 , it is observed that the value of $\lambda$ for plyangle $30^{\circ} /-30^{\circ}$ increases and then decreases multiple times throughout $0.5 \leq \eta \leq 1.9$. The frequency values for plyangle $45^{\circ} /-45^{\circ}$ increase up to $\eta=1.1$ and then decrease afterwards. The frequency for two-layered shell with ply angle $60^{\circ} /-60^{\circ}$ shows a steady decrease throughout $0.5 \leq$ $\eta \leq 1.9$. The value of $\lambda$ increases up to $\eta=1.3$ and then decreases with the increase of $\eta$ for four-layered shell with ply-angle $30^{\circ} /-30^{\circ} / 30^{\circ} /-30^{\circ}$. In the case of ply-angles $45^{\circ} /-45^{\circ} / 45^{\circ} /-45^{\circ}$ and $60^{\circ} /-60^{\circ} / 60^{\circ} /-60^{\circ}$, the value of $\lambda$ decreases as $\eta$ decreases. The influence of $\eta$ towards the fundamental frequency parameter $\lambda$ for two-layered and fourlayered antisymmetric angle-ply shells under S-S boundary condition is demonstrated in Table 4. Tables 5 and 6 show the effects of exponential variation of thickness on the fundamental frequency parameter for two-layered and four-layered antisymmetric angle-ply shells under $\mathrm{C}-\mathrm{C}$ and $\mathrm{S}-\mathrm{S}$ boundary conditions respectively. In Tables $4-6$, the variation of fre- 


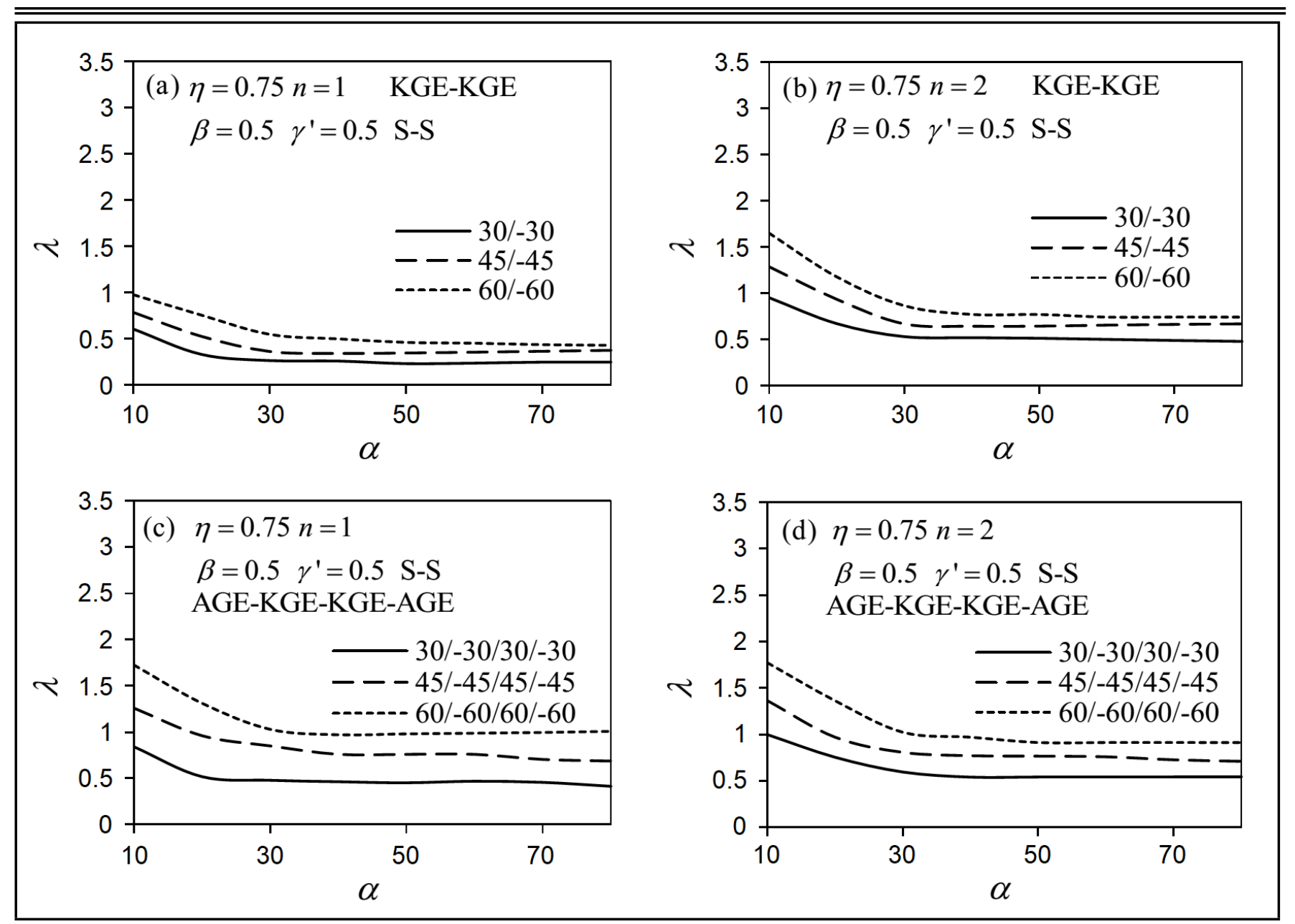

Figure 2. Effect of cone angle on fundamental frequency parameter of two-layered and four-layered conical shells under S-S boundary condition: linear variation in thickness.

quency parameter shows the same pattern as shown in Table 3. In Tables 3-6, the frequency values are higher for two-layered shells as compared to the corresponding values of four-layered shells. Moreover, the values of the fundamental frequency parameter are lower for S-S boundary condition as compare to C-C boundary condition.

Figure 1 illustrates the fundamental frequency parameter $\lambda$ versus the cone angle $\alpha$. Figures 1a and 1b show the variation of $\lambda$ against cone angle $\alpha$ for two-layered angle-ply shells with ply-angles $30^{\circ} /-30^{\circ}, 45^{\circ} /-45^{\circ}$ and $60^{\circ} /-60^{\circ}$ whereas Figs. 1c and 1d represent the influence of $\alpha$ towards the fundamental frequency value $\lambda$ for four-layered shells with ply-angles $30^{\circ} /-30^{\circ} / 30^{\circ} /-30^{\circ}, 45^{\circ} /-45^{\circ} / 45^{\circ} /-45^{\circ}$ and $60^{\circ} /-60^{\circ} / 60^{\circ} /-60^{\circ}$. The parameters $\eta=0.75, \beta=0.5$, $\gamma^{\prime}=0.5, n=1$ and $n=2$ are fixed. As can be seen in Figs. $1 \mathrm{a}-1 \mathrm{~d}$, the value of $\lambda$ steadily decreases from $\alpha=10^{\circ}$ until $\alpha=50^{\circ}$ and becomes stable afterwards. Also, the frequency values are higher for higher angles and the value of $\lambda$ decreases when $\alpha$ increases. The effect of cone angle $\alpha$ with respect to the frequency parameter value $\lambda$ is depicted in Fig. 2 by fixing other parameters. The results in Fig. 2 show the same pattern as shown in Fig. 1. The decrease of $\lambda$ is up to $\alpha=30^{\circ}$ and then the value of $\lambda$ remains almost unchanged for $\alpha \geq 30^{\circ}$.

In Fig. 3, the variation of fundamental angular frequency $\omega$ with respect to the length ratio $\beta$ is presented for two-layered shells. Since frequency parameter $\lambda$ is a function of length, $l$ of a conical shell, the variation of $\omega$ is analysed. The value $\alpha=30^{\circ}, \gamma=0.05, n=1, n=2, \eta=0.75$ and $\eta=1.75$ are fixed. As can be seen in Fig. 3, the angular frequencies increase steadily up to some value of $\beta$ and then rise significantly afterwards. Higher angles result in higher fundamental angular frequency values and the value of $\omega$ increases when $\beta$ increases. Figure 4 presents the fundamental angular frequency $\omega$ subjected to different length ratios $\beta$ for four-layered shells. All graphs in Fig. 4 show similar vibrational pattern with the corresponding case of two-layered shell in Fig. 3. However, the frequency values for four-layered shells are higher than the corresponding frequency values for two-layered shells.

Figures $5 \mathrm{a}$ and $5 \mathrm{~b}$ depict the variation of fundamental angular frequency $\omega$ with respect to the length ratio $\beta$ for twolayered and four-layered conical shells respectively. In Fig. 5a, conical shell with ply-angle $60^{\circ} /-60^{\circ}$ for length ratio 0.1 until 0.65 has the highest angular frequency values when compared with the other two ply-angles but changes into the lowest from 0.65 until 0.8 . Conical shell with ply-angle $60^{\circ} /-60^{\circ} / 60^{\circ} /-60^{\circ}$ in Fig. $5 \mathrm{~b}$ also shows the same pattern since it has the highest frequencies from 0.1 until 0.55 but switches into the lowest from 0.55 until 0.8 . As observed, the angular frequencies for four-layered shells are higher than corresponding two-layered shells. The manner of variation of fundamental angular frequency $\omega$ with respect to the length ratio $\beta$ for two-layered and four-layered conical shells for $\alpha=30^{\circ}$ and $\alpha=60^{\circ}$ under S-S boundary condition is shown in Fig. 6 . It is seen that the frequencies are lower for higher angles. 


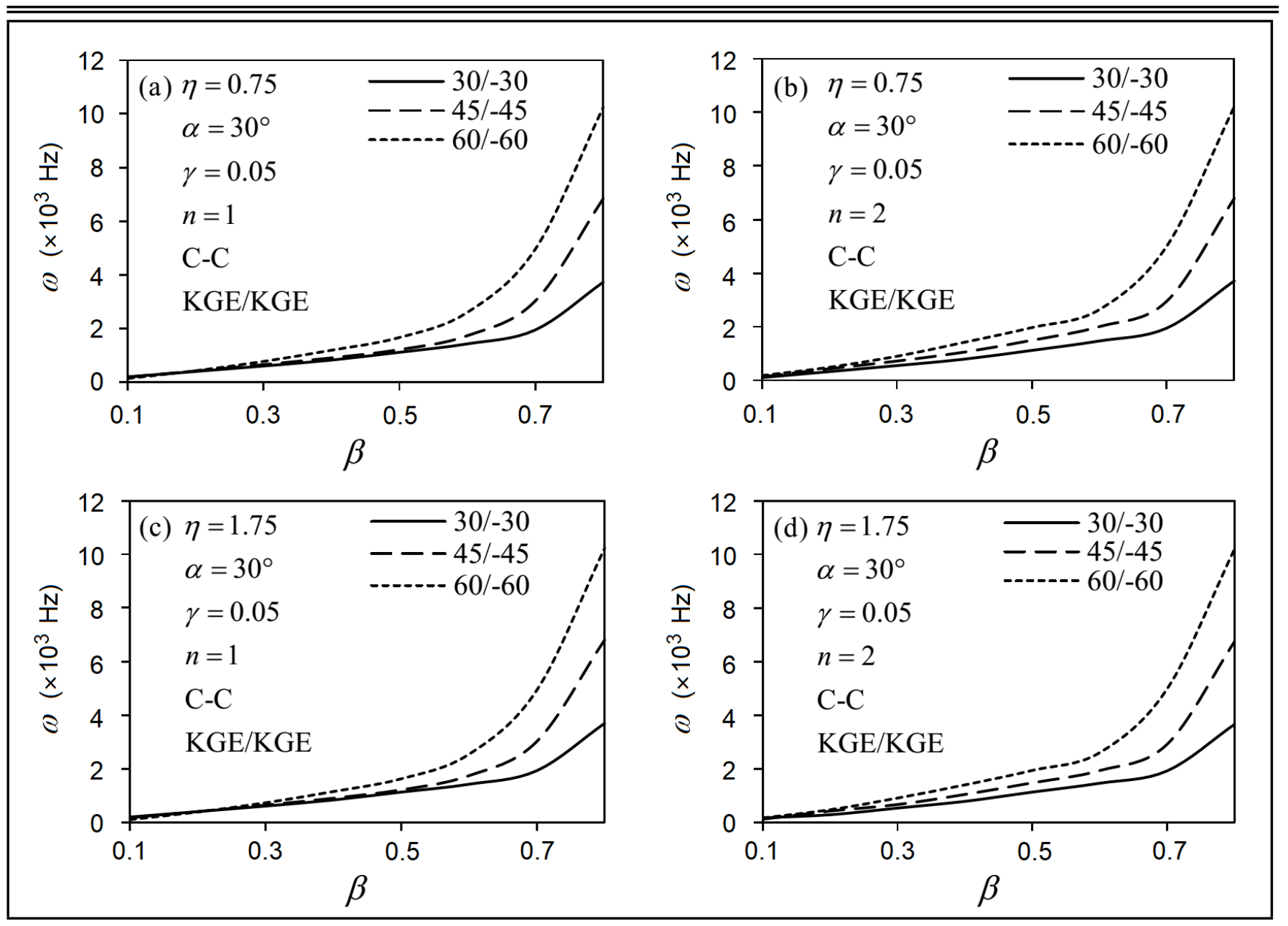

Figure 3. Effect of length ratio on fundamental angular frequency of two-layered conical shell when $\alpha=30^{\circ}$ is under C-C boundary condition: linear variation in thickness.
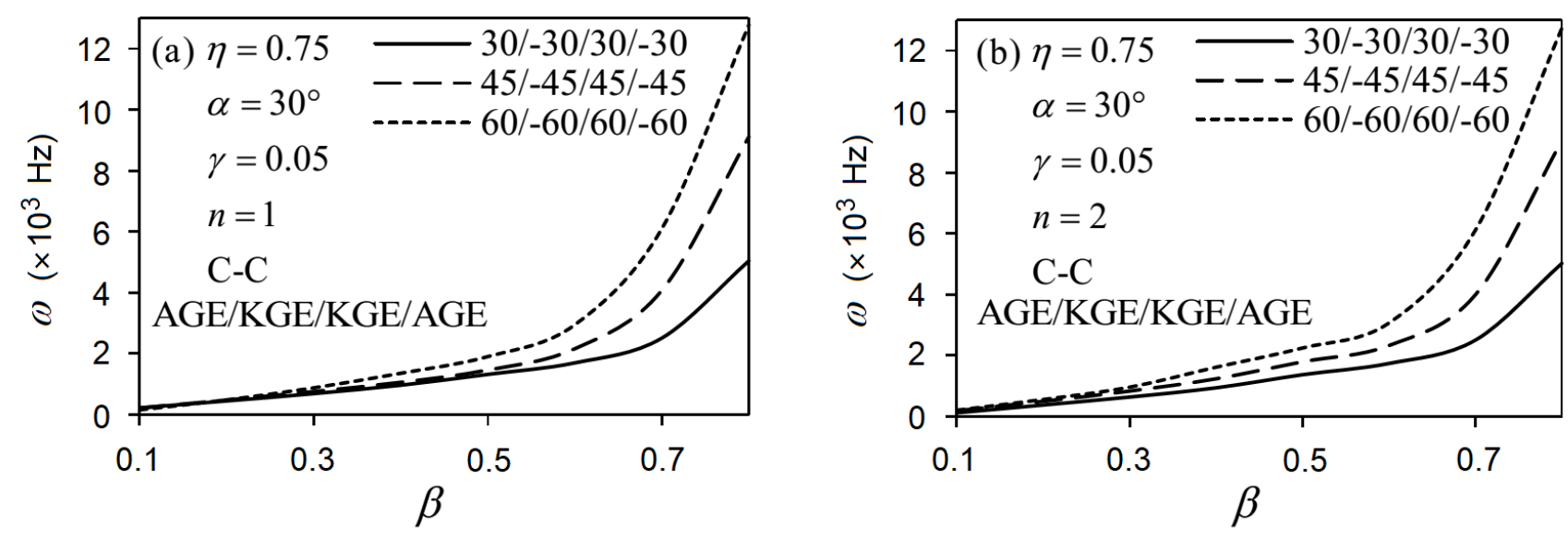

Figure 4. Effect of length ratio on fundamental angular frequency of four-layered conical shell when $\alpha=30^{\circ}$ is under C-C boundary condition: linear variation in thickness.

Figures 7 and 8 indicate the variation of frequency parameter $\lambda$ for two-layered and four-layered conical shells with respect to cone angel $\alpha$ for exponential variation in thickness by fixing the parameters $C_{e}, \beta$ and $\gamma^{\prime}$. Figure 7 relates to the shells with $\mathrm{C}-\mathrm{C}$ boundary condition while Fig. 8 uses S$\mathrm{S}$ boundary condition. Based on Figs. 7 and 8, the value of $\lambda$ is higher for higher angles for both conical shells under C-C and $\mathrm{S}-\mathrm{S}$ boundary conditions, but the frequency parameter values for S-S boundary condition are lower than corresponding values for C-C boundary condition. The fundamental angular frequency $\omega$ for two-layered antisymmetric angle-ply conical shells with the influence of length ratio $\beta$ when $\alpha=30^{\circ}$ for exponential variation in thickness under C-C boundary condition is depicted in Fig. 9. Figure 9a shows the variation of angular frequencies with thickness variation coefficient $C_{e}=-0.2$ whereas Fig. 9b depicts the distribution of frequencies when $C_{e}=0.2$. From Figs. $9 \mathrm{a}$ and $9 \mathrm{~b}$, it is seen that different value of exponential variation in thickness does not significantly af- 


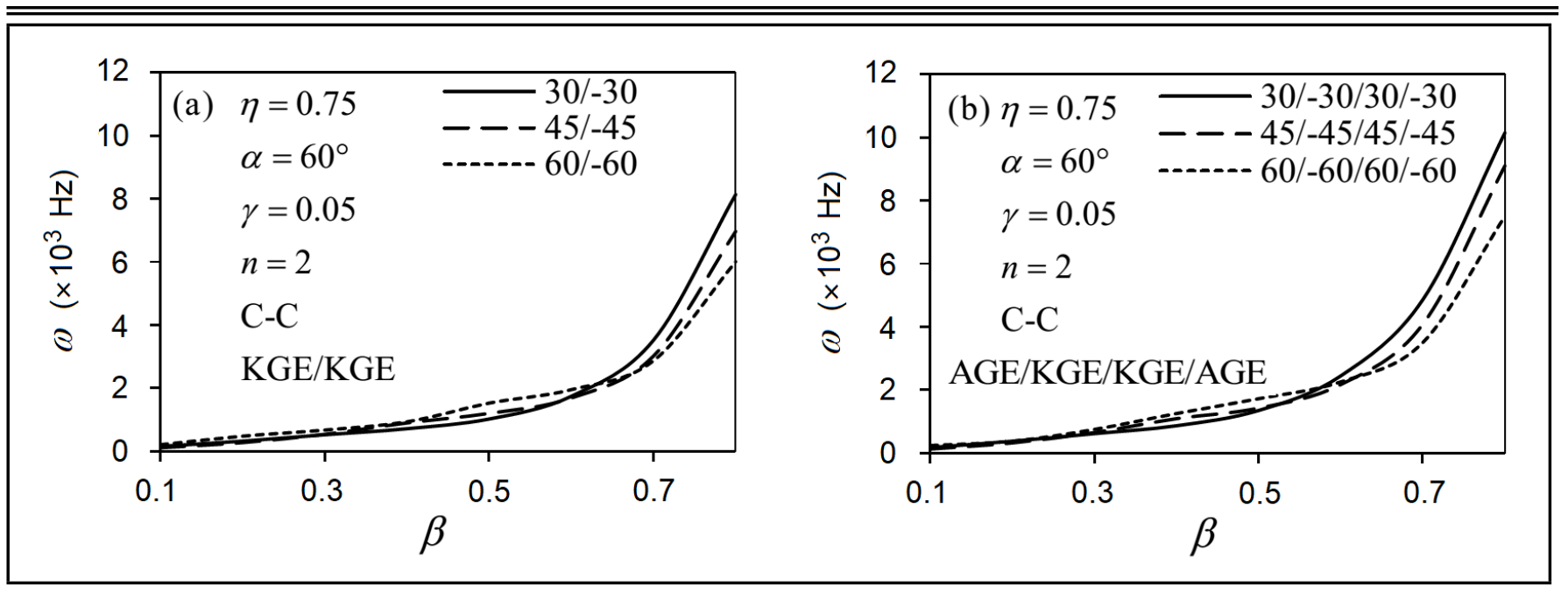

Figure 5. Effect of length ratio on fundamental angular frequency of two-layered and four-layered conical shell when $\alpha=60^{\circ}$ is under C-C boundary condition: linear variation in thickness.
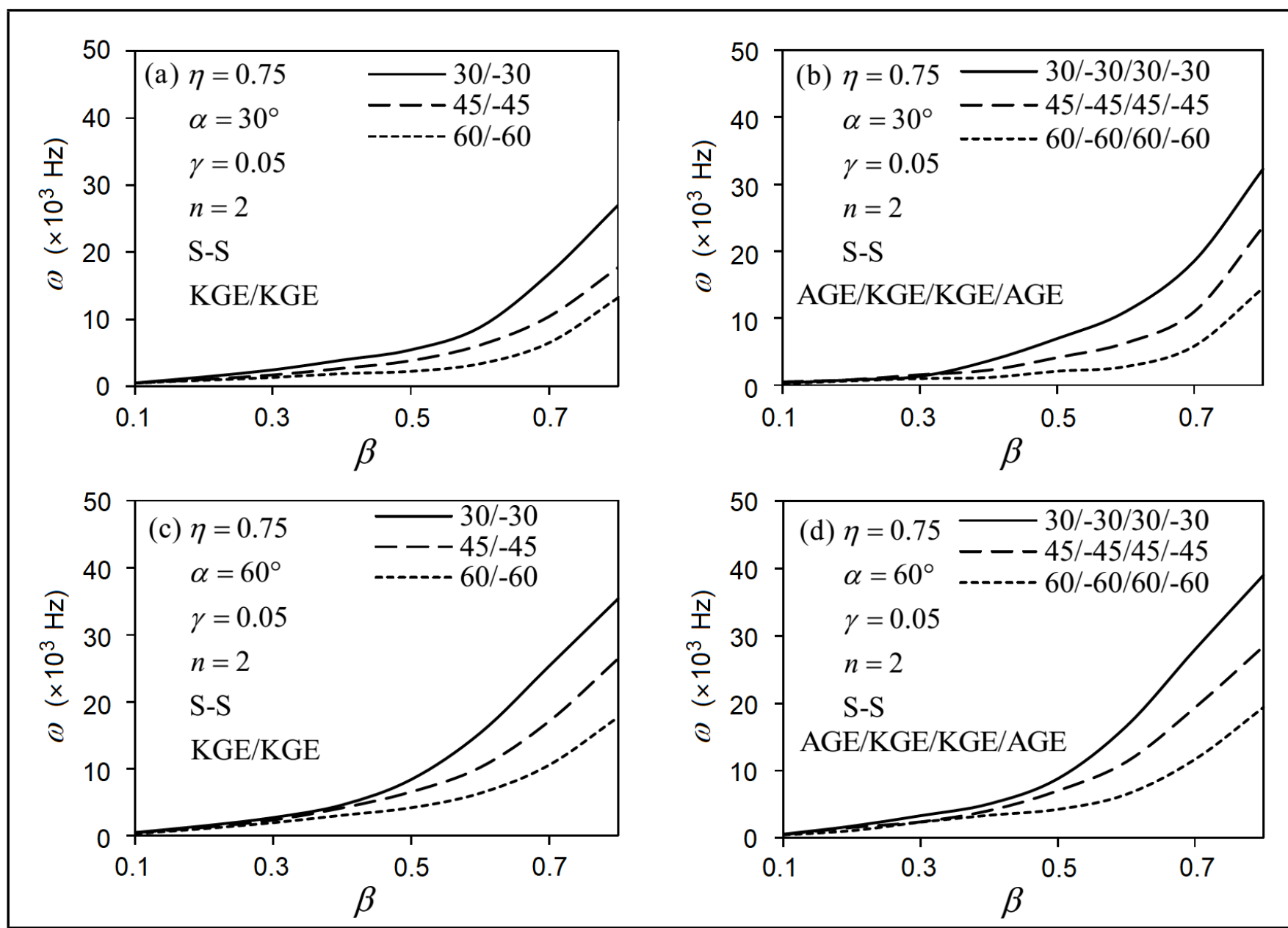

Figure 6. Effect of length ratio on fundamental angular frequency of two-layered and four-layered conical shell for $\alpha=30^{\circ}$ and $\alpha=60^{\circ}$ under C-C boundary condition: linear variation in thickness.

fect the angular frequencies of conical shells. The fundamental angular frequency $\omega$ versus the length ratio $\beta$ for four-layered conical shells is shown in Fig. 10. The shells have cone angle $\alpha=30^{\circ}, C_{e}=0.2, n=1, n=2$ and $\gamma=0.05$. The fundamental frequency $\omega$ is higher for four-layered shell compared to the values of $\omega$ for two-layered shell with the corresponding angles.

Figures $11 \mathrm{a}$ and $11 \mathrm{~b}$ describe the influence of length ratio $\beta$ on angular frequency $\omega$ of two-layered and four-layered conical shells respectively. The thickness variation coefficient $C_{e}=0.2$ and other parameters are held fixed. The vibrational behaviour of these shells is similar to the case in Fig. 5. Figure 12 depicts the effect of length ratio $\beta$ on angular frequency $\omega$ of two-layered and four-layered conical shells for cone angle $\alpha=30^{\circ}$ and $\alpha=60^{\circ}$ under S-S boundary condition. Analysing from Fig. 12, we can see that the angular frequencies for conical shells with cone angle $\alpha=30^{\circ}$ are lower when compared to the corresponding values of $\alpha=60^{\circ}$. 


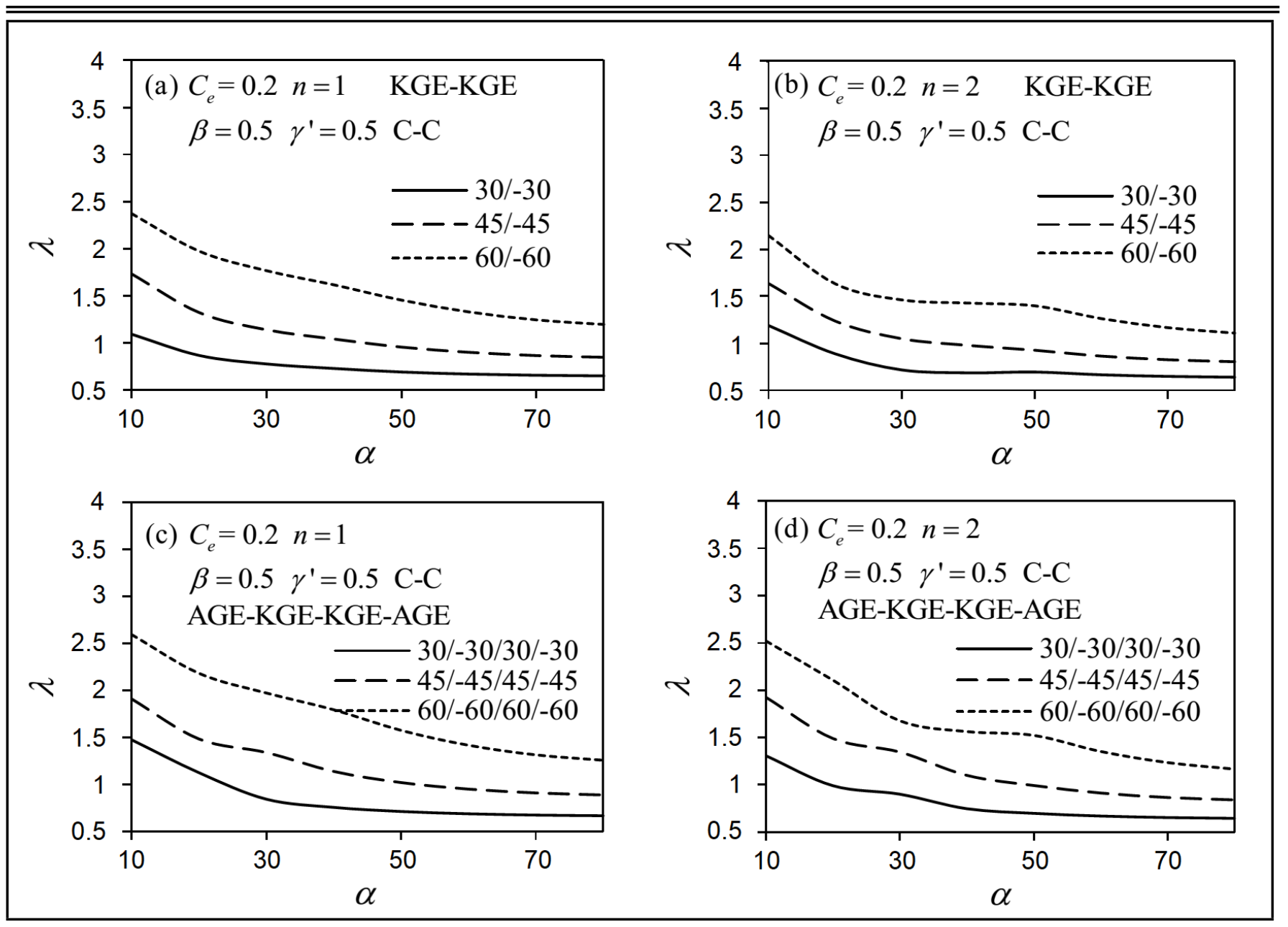

Figure 7. Effect of cone angle on fundamental frequency parameter of two-layered and four-layered conical shells under C-C boundary condition: : exponential variation in thickness.
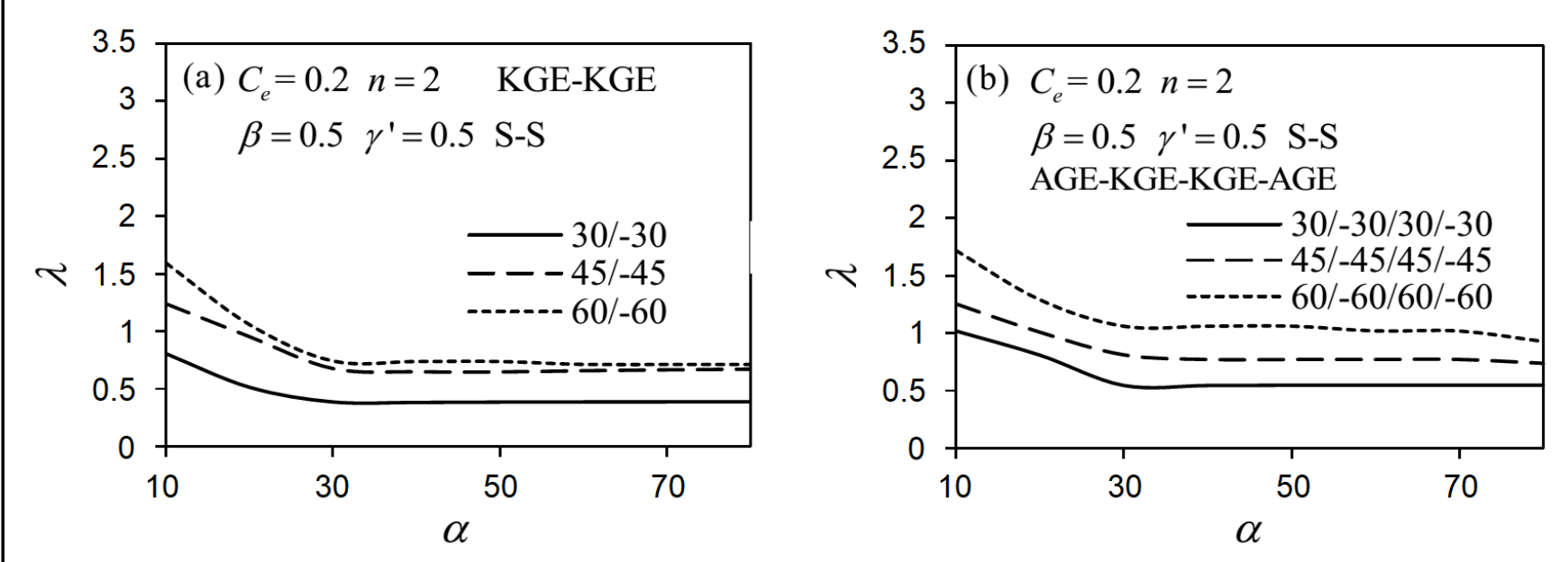

Figure 8. Effect of cone angle on fundamental frequency parameter of two-layered and four-layered conical shells under S-S boundary condition: : exponential variation in thickness.

\section{CONCLUSION}

The effect of linear and exponential thickness in variation, cone angle, length ratio, circumferential node number, different lamination materials, ply-angles, and two different boundary conditions on the free vibration of conical shells using spline approximation technique is analysed. Antisymmetric angle-ply laminations for two-layered and four-layered shells are considered. It is concluded from the results that the value of the frequency parameter strictly decreases for certain value of cone angle and become steady afterwards with the increase of cone angle. Also, the angular frequency values remain steady for certain value of length ratio and strictly increases afterwards as the length ratio increases. Further, S-S boundary condition results in lower value of frequency parameter as compare to $\mathrm{C}-\mathrm{C}$ boundary condition. The results presented in this paper may be fruitful for designers in related fields for designing the conical shell structure according to their needs. 


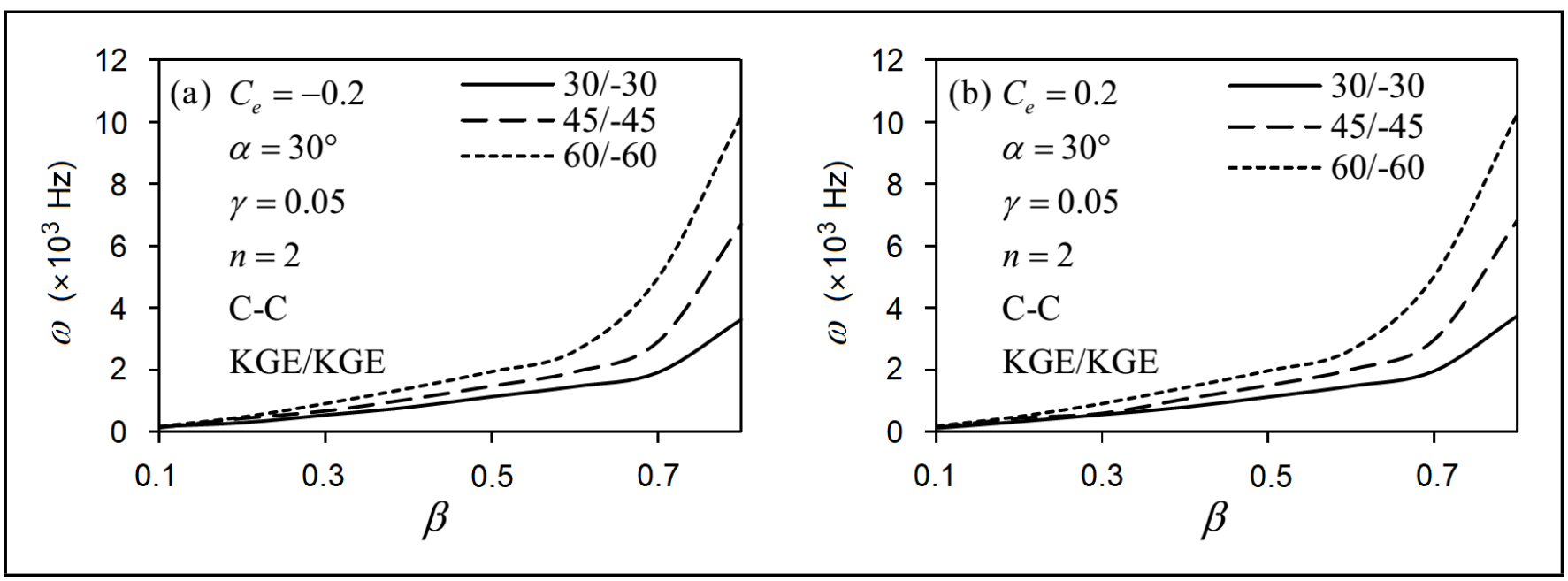

Figure 9. Effect of length ratio on fundamental angular frequency of two-layered conical shells when $\alpha=30^{\circ}$ under C-C boundary condition: exponential variation in thickness.

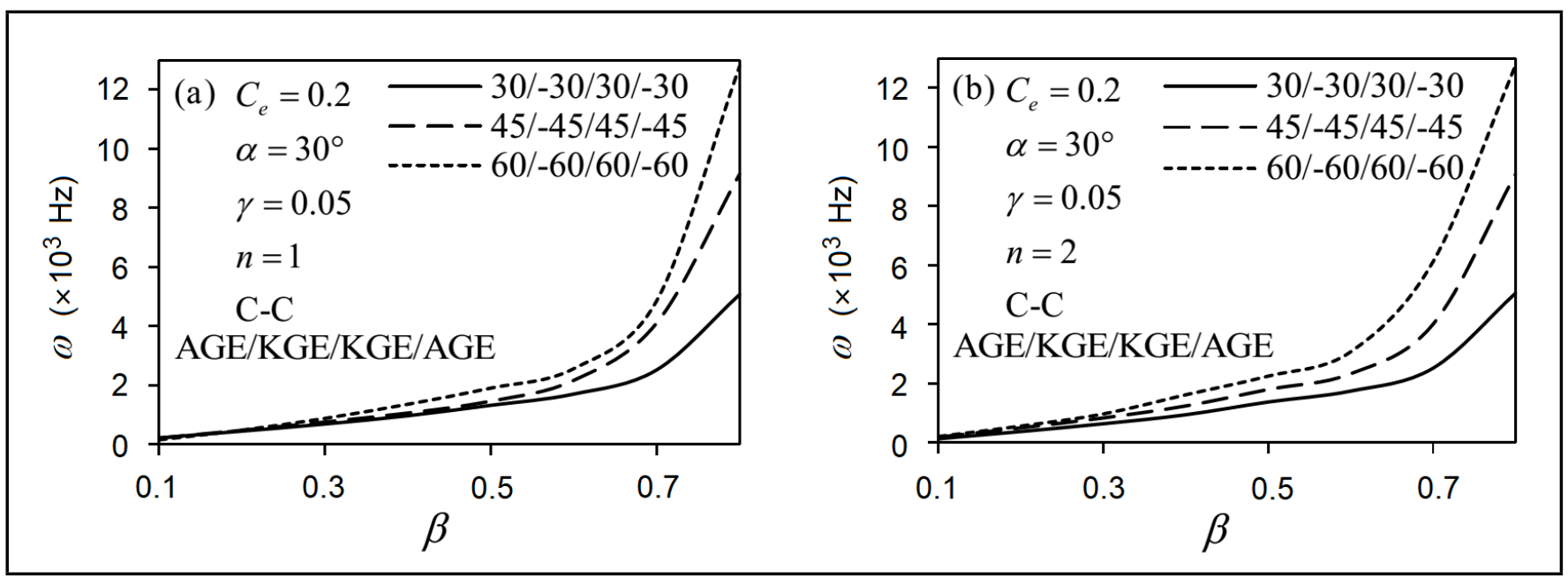

Figure 10. Effect of length ratio on fundamental angular frequency of two-layered conical shells when $\alpha=30^{\circ}$ under C-C boundary condition: exponential variation in thickness.
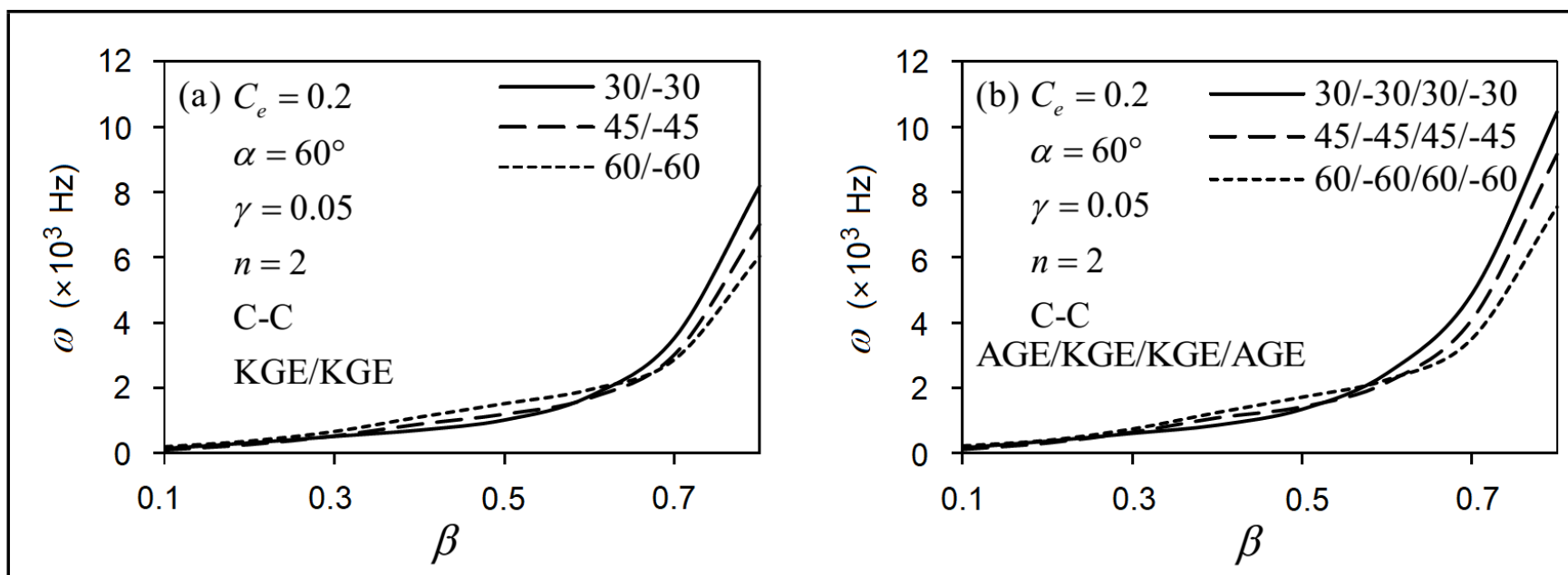

Figure 11. Effect of length ratio on fundamental angular frequency of two-layered and four-layered conical shells when $\alpha=60^{\circ}$ under $\mathrm{C}-\mathrm{C}$ boundary condition: exponential variation in thickness. 




Figure 12. Effect of length ratio on fundamental angular frequency of two-layered and four-layered conical shells for $\alpha=30^{\circ}$ and $\alpha=60^{\circ}$ under S-S boundary condition: exponential variation in thickness.

\section{ACKNOWLEDGEMENTS}

This work was supported by MOHE, Project Vote No. 05H78 under Research management Centre (RMC), Universiti Teknologi Malaysia, Malaysia and also supported by My Brain 15. Malaysia.

\section{REFERENCES}

$1 \mathrm{Wu}$, C. P. and Wu, C. H. Asymptotic differential quadrature solutions for the free vibration of laminated conical shells, Computational Mechanics, 25, 346-35, (2000). https://dx.doi.org/10.1007/s00466005048

2 Tong, L. Free vibration of orthotropic conical shells, International Journal of Engineering Science, 31 (5), 719-733, (1993). https://dx.doi.org/10.1016/0020-7225(93)90120-j

3 Tong, L. Free vibration of laminated conical shells including transverse shear deformation, International Journal of Engineering Science, 31 (4), 443-456, (1994). https://dx.doi.org/10.1016/0020-7683(94)90085-x

4 Tong, L. Effects of transverse shear deformation on free vibration of orthotropic conical shells, Acta Mechanica, 107, 65-75, (1994). https://dx.doi.org/10.1007/bf01201820

5 Shu, C. Free vibration analysis of composite laminated conical shells by generalized differential quadrature, Jour- nal of Sound and Vibration, 194 (4), 587-604, (1996). https://dx.doi.org/10.1006/jsvi.1996.0379

6 Ng, T. Y., Li, H., and Lam, K. Y. Generalized differential quadrature for free vibration of rotating composite laminated conical shell with various boundary conditions, International Journal of Mechanical Sciences, 45, 567-587, (2003). https://dx.doi.org/10.1016/s0020-7403(03)00042-0

7 Civalek, O. Vibration analysis of conical panels using the method of discrete singular convolution, Communications in Numerical Methods in Engineering, 24, 169-181, (2006). https://dx.doi.org/10.1002/cnm.961

8 Civalek, O. Vibration analysis of laminated composite conical shells by the method of discrete singular convolution based on the shear deformation theory, Composites Part B: Engineering, 45, 1001-1009, (2013). https://dx.doi.org/10.1016/j.compositesb.2012.05.018

9 Liew, K. M., Ng, T. Y., and Zhao, X. Free vibration analysis of conical shells via the element-free kp-Ritz method, Journal of Sound and Vibration, 281, 627-645, (2005). https://dx.doi.org/10.1016/j.jsv.2004.01.005

10 Liew, K. M. and Zhao, X. Free vibration analysis of functionally graded conical shell panels by a meshless method, Composite Structures, 93, 649-664, (2011). https://dx.doi.org/10.1016/j.compstruct.2010.08.014 
11 Viswanathan, K. K., Lee, J. H., Aziz, Z. A., Hossain, I., Rongqio, W., and Abdullah, H. Y. Vibration analysis of cross-ply laminated truncated conical shells using a spline method, Journal of Engineering Mathematics, 76, 139-56, (2012). https://dx.doi.org/10.1007/s10665-011-9525-x

12 Viswanathan, K. K., Javed, S., and Aziz, Z. A. Free vibration of symmetric angle-ply layered conical shell frusta of variable thickness under shear deformation theory, Structural Engineering and Mechanics, 45 (2), 259-275, (2013). https://dx.doi.org/10.12989/sem.2013.45.2.259

13 Viswanathan, K. K., Javed, S., Prabakar, K., Aziz, A., and Bakar, I. A. Free vibration of antisymmetric angle-ply laminated conical shells, Composite Structures, 122, 488-495, (2015). https://dx.doi.org/10.1016/j.compstruct.2014.11.075

14 Dey, S. and Karmakar, A. Free vibration analyses of multiple delaminated angle-ply composite conical shells-a finite element approach, Composite Structures, 94, 2188-2196, (2012). https://dx.doi.org/10.1016/j.compstruct.2012.01.006

15 Farshidianfar, A. and Olizadech, P. Free vibration analysis of circular cylindrical shells: comparison of different shell theories, International Journal of Mechanics and Applications, 2 (5), 74-80, (2012). https://dx.doi.org/10.5923/j.mechanics.20120205.04

16 Jin, G., Ma, X., Shi, S., Ye, T., and Liu, Z. A modified Fourier series solution for vibration analysis of truncated conical shells with general boundary conditions, Applied Acoustics, 85, 82-96, (2014). https://dx.doi.org/10.1016/j.apacoust.2014.04.007

17 Malekzadech, P. and Daraie, M. Dynamic analysis of functionally graded truncated conical shells subjected to asymmetric moving loads, Thin-Walled Structures, 84, 1-13, (2014). https://dx.doi.org/10.1016/j.tws.2014.05.007

18 Ma, X., Jin, G., Xiong, Y., and Liu, Z. Free and forced vibration analysis of coupled conical-cylindrical shells with arbitrary boundary conditions, International Journal of Mechanical Sciences, 88, 122-137, (2014). https://dx.doi.org/10.1016/j.ijmecsci.2014.08.002

19 Zaroumi, E., Rad, M. J., and Tohidi, H. Free vibration analysis of fiber reinforced composite conical shells resting on Pasternak-type elastic foundation using Ritz and Galerkin methods, International Journal of Mechanics and Materials, 10, 421-438, (2014). https://dx.doi.org/10.1007/s10999-014-9254-1

${ }^{20}$ Heydarpour, Y., Aghdam, M. M., and Malekzadeh, P. Free vibration analysis of rotating functionally graded carbon nanotube-reinforced composite truncated conical shells, Composite Structures, 117, 187-200, (2014). https://dx.doi.org/10.1016/j.compstruct.2014.06.023

${ }^{21}$ Irie, T., Yamada, G., and Kaneko, Y. Free vibration of a conical shell with variable thickness, Journal of Sound and Vibration, 82 (1), 83-94, (1982). https://dx.doi.org/10.1016/0022-460x(82)90544-2
22 Sankaranayanan, N., Chandrasekaran, K., and Ramaiyan, G. Axisymmetric vibrations of laminated conical shells of variable thickness, Journal of Sound and Vibration, 118, 151-161, (1987). https://dx.doi.org/10.1016/0022$460 x(87) 90260-4$

23 Takahashi, S., Suzuki, K., and Kosawada, T. Vibrations of conical shells with variable thickness, Bulletin of JSME, 29 (258), 4306-4311, (1986). https://dx.doi.org/10.1299/jsme1958.29.4306

${ }^{24}$ Sivadas, K. R. and Ganesan, N. Free vibration of cantilever conical shells with variable thickness, Computers and Structures, 36 (3), 559-566, (1990). https://dx.doi.org/10.1016/0045-7949(90)90290-i

25 Sivadas, K. R. and Ganesan, N. Vibration analysis of laminated conical shells with variable thickness, Journal of Sound and Vibration, 148 (3), 477-491, (1991). https://dx.doi.org/10.1016/0022-460x(91)90479-4

${ }^{26}$ Kang, J. H. Vibration analysis of complete conical shells with variable thickness, International Journal of Structural Stability and Dynamics, 14 (4), 1450001-14500024, (2014). https://dx.doi.org/10.1142/s0219455414500011

27 Selahi, E., Setoodeh, A. R., and Tahani, M. Threedimensional transient analysis of functionally graded truncated conical shells with variable thickness subjected to an asymmetric dynamic pressure, International Journal of Pressure Vessels and Piping, 119, 29-38, (2014). https://dx.doi.org/10.1016/j.ijpvp.2014.02.003

${ }^{28}$ Mehdi, J., Mohammad, Z. N., and Mehdi, G. Thermoelastic analysis of axially functionally graded rotating thick truncated conical shells with varying thickness, Composites Part B: Engineering, 96, 20-34, (2016). https://dx.doi.org/10.1016/j.compositesb.2016.04.026

${ }^{29}$ Bickley, W. G. Piecewise cubic interpolation and two-point boundary problems, The Computer Journal, 11 (2), 206208, (1968). https://dx.doi.org/10.1093/comjn1/11.2.206

30 Whitney, J. M. Shear correction factor for orthotropic laminates under static load, Journal of Applied Mechanics, 37, 1032-1036, (1973). https://dx.doi.org/10.1115/1.3422950

${ }^{31}$ Daneshjou, K., Talebitooti, M., and Talebitooti, R. Free vibration and critical speed of moderately thick rotating laminated composite conical shell using generalized differential quadrature method, Applied Mathematics and Mechanics, 34 (4), 437-56, (2013). https://dx.doi.org/10.1007/s10483013-1682-8

${ }^{32}$ Lam, K. Y. and Hua, L. Influence of boundary conditions on the frequency characteristics of a rotating truncated circular conical shells, Journal of Sound and Vibration, 223, 17195, (1999). https://dx.doi.org/10.1006/jsvi.1998.1432

33 Irie, T., Yamada, G., and Tanaka, K. Natural frequencies of truncated conical shells, Journal of Sound and Vibration, 92, 447-53, (1984). https://dx.doi.org/10.1016/0022$460 x(84) 90391-2$ 


\section{APPENDIX A}

The differential operators $L_{i j}$ of the matrix are

$L_{11}=\frac{d^{2}}{d X^{2}}+\left(\frac{g^{\prime}}{g}+p\right) \frac{d}{d X}+S_{2} \frac{g^{\prime}}{g} p-S_{3} p^{2}+$ $S_{10} n^{2} p^{2} \csc ^{2} \alpha+\lambda^{2}$;

$L_{12}=\left(S_{2}+S_{10}\right) n p \csc \alpha \frac{d}{d X}+$ $\left(S_{2} \frac{g^{\prime}}{g}-S_{3} p-S_{10} p\right) n p \csc \alpha$

(A.1)

$L_{13}=S_{2} p \cot \alpha \frac{d}{d X}+\left(S_{2} \frac{g^{\prime}}{g}-S_{3} p\right) p \cot \alpha ;$

$L_{14}=2 S_{15} n p \csc \alpha \frac{d}{d X}+S_{15} \frac{g^{\prime}}{g} n p \csc \alpha$;

$L_{15}=S_{15} \frac{d^{2}}{d X^{2}}+\left(S_{15} \frac{g^{\prime}}{g}-S_{16} p\right) \frac{d}{d X}+$

$$
\left(S_{16} p+S_{16} n^{2} p \csc ^{2} \alpha-S_{15} \frac{g^{\prime}}{g}\right) p ;
$$

$L_{21}=\left(S_{2}+S_{10}\right) n p \csc \alpha \frac{d}{d X}+$

$$
\left(S_{10} \frac{g^{\prime}}{g}+S_{10} p+S_{3} p\right) n p \csc \alpha
$$

$L_{22}=S_{10} \frac{d^{2}}{d X^{2}}+S_{10}\left(\frac{g^{\prime}}{g}+p\right) \frac{d}{d X}+$

$\left(-S_{10} \frac{g^{\prime}}{g}-S_{10} p-k S_{13} \cot ^{2} \alpha+S_{3} p n^{2} \csc ^{2} \alpha\right) p+$ $\lambda^{2}$

$L_{23}=\left(S_{3}+k S_{13}\right) p^{2} n \csc \alpha \cot \alpha ;$

$L_{24}=S_{15} \frac{d^{2}}{d X^{2}}+\left(S_{15} \frac{g^{\prime}}{g}+S_{16} p+2 S_{15} p\right) \frac{d}{d X}+$ $S_{16}\left(\frac{g^{\prime}}{g}+p+p n^{2} \csc ^{2} \alpha\right) p$

$L_{25}=2 S_{16} p n \csc \alpha \frac{d}{d X}+\left(k S_{13} \cot \alpha+S_{16} \frac{g^{\prime}}{g} n \csc \alpha\right) p$;

$L_{31}=-S_{2} p \cot \alpha \frac{d}{d X}-S_{3} p^{2} \cot \alpha$

$L_{32}=\left(-S_{3}-k S_{13}\right) p^{2} n \csc \alpha \cot \alpha ;$

$L_{33}=k S_{14} \frac{d^{2}}{d X^{2}}+k S_{14}\left(\frac{g^{\prime}}{g}+p\right) \frac{d}{d X}+$

$\left(-S_{3} \cot ^{2} \alpha+k S_{13} n^{2} \csc ^{2} \alpha\right) p^{2}+\lambda^{2}$

$L_{34}=k S_{14} \frac{d}{d X}-S_{16} p^{2} n \csc \alpha \cot \alpha+k S_{14} \frac{g^{\prime}}{g}+k S_{14} p$;

$L_{35}=-S_{16} p \cot \alpha \frac{d}{d X}+\left(k S_{13} n \csc \alpha+S_{16} p \cot \alpha\right) p$

$L_{41}=2 S_{15} n p \csc \alpha \frac{d}{d X}+S_{15} \frac{g^{\prime}}{g} n p \csc \alpha$

$$
\begin{aligned}
L_{42}= & S_{15} \frac{d^{2}}{d X^{2}}+\left(S_{15} \frac{g^{\prime}}{g}-S_{16} p\right) \frac{d}{d X}+ \\
& \left(-S_{15} \frac{g^{\prime}}{g}+S_{16} p+S_{16} p n^{2} \csc ^{2} \alpha\right) p \\
L_{43}= & -k S_{14} \frac{d}{d X}+S_{16} p^{2} n \csc \alpha \cot \alpha \\
L_{44}= & S_{7} \frac{d^{2}}{d X^{2}}+S_{7}\left(\frac{g^{\prime}}{g}+p\right) \frac{d}{d X}+ \\
& \left(S_{8} \frac{g^{\prime}}{g} p-S_{9} p^{2}+S_{12} p^{2} n^{2} \csc ^{2} \alpha-k S_{14}\right)+\lambda^{2} p_{1} ;
\end{aligned}
$$

$L_{45}=\left(S_{8} n \csc \alpha+S_{12} n \csc \alpha\right) p \frac{d}{d X}+$

$$
\left(S_{8} \frac{g^{\prime}}{g}-S_{9} p-S_{12} p\right) p n \csc \alpha
$$

$L_{51}=S_{15} \frac{d^{2}}{d X^{2}}+\left(S_{15} \frac{g^{\prime}}{g}+2 S_{15} p+S_{16} p\right) \frac{d}{d X}+$

$$
S_{16}\left(\frac{g^{\prime}}{g}+p+p n^{2} \csc ^{2} \alpha\right) p
$$

$L_{52}=2 S_{16} p n \csc \alpha \frac{d}{d X}+\left(S_{16} \frac{g^{\prime}}{g} n \csc \alpha+k S_{13} \cot \alpha\right) p ;$

$L_{53}=S_{16} p \cot \alpha \frac{d}{d X}+$

$$
\left(S_{16} \frac{g^{\prime}}{g} \cot \alpha-k S_{13} n \csc \alpha+S_{16} p \cot \alpha\right) p
$$

$$
\begin{aligned}
L_{54}= & \left(S_{12}+S_{8}\right) p n \csc \alpha \frac{d}{d X}+ \\
& \left(S_{12} \frac{g^{\prime}}{g}+S_{12} p+S_{9} p\right) p n \csc \alpha
\end{aligned}
$$

$$
\begin{aligned}
L_{55}= & S_{12} \frac{d^{2}}{d X^{2}}+S_{12}\left(\frac{g^{\prime}}{g}+p\right) \frac{d}{d X}- \\
& \left(S_{12} \frac{g^{\prime}}{g} p+S_{12} p^{2}-S_{9} p^{2} n^{2} \csc ^{2} \alpha+k S_{13}\right)+\lambda^{2} p_{1} .
\end{aligned}
$$

The quantities $S_{i}(i=1,2, \ldots, 14)$ are defined by

$$
\begin{aligned}
& S_{2}=\frac{A_{12}}{A_{11}} ; \quad S_{3}=\frac{A_{22}}{A_{11}} ; \quad S_{7}=\frac{D_{11}}{l^{2} A_{11}} ; \quad S_{8}=\frac{D_{12}}{l^{2} A_{11}} ; \\
& S_{9}=\frac{D_{22}}{l^{2} A_{11}} ; \quad S_{10}=\frac{A_{66}}{A_{11}} ; \quad S_{12}=\frac{D_{66}}{l^{2} A_{11}} ; \quad S_{13}=\frac{A_{44}}{A_{11}} ; \\
& S_{14}=\frac{A_{55}}{A_{11}} ; \quad S_{15}=\frac{B_{16}}{A_{11}} ; \quad S_{16}=\frac{B_{26}}{A_{11}} ;
\end{aligned}
$$

